
\title{
CARACTERIZAÇÃO E DISTRIBUIÇÃO DA PRECIPITAÇÃO NO
MUNICÍPIO DE LEÓPOLIS, PR
}

\author{
R. T. de Lima*
}

\author{
UFPR - Universidade Federal do Paraná, Curitiba, PR, Brasil
}

Article history: Received 05 June 2019; Received in revised form 10 June 2019; Accepted 12 June 2019; Available online 24 June 2019.

\section{RESUMO}

O município de Leópolis, localizado no norte do estado do Paraná, possui estações pluviométricas em funcionamento desde o ano de 1976, no entanto nenhum estudo fora realizado para a caracterização e variabilidade das precipitações específico para o município, sendo esse tipo de informação indispensável para o planejamento agrícola e urbano. Nesse sentido, o objetivo do trabalho foi caracterizar e avaliar a variabilidade anual, mensal bem como quantificar o número de dias chuvosos e secos, além de definir diferentes níveis de probabilidade de precipitação. Foram utilizados dados pluviométricos disponibilizados pelo Instituto das Águas do Paraná, do período de janeiro de 1976 a dezembro de 2017, totalizando um histórico ininterrupto de 42 anos. A precipitação em Leópolis caracteriza-se com os maiores índices pluviométricos no período de setembro a maio e os menores de junho a agosto. Nos anos de 2015 e 1988 ocorreram a maior e menor precipitação anual respectivamente. A precipitação média anual do período foi de $1380,10 \mathrm{~mm}$. Com a utilização da função gama incompleta foi possível expressar adequadamente a probabilidade de precipitação em Leópolis, estando as médias mensais de precipitação entre 40 a $50 \%$ de probabilidade para os meses de maior precipitação e entre 25 a $40 \%$ para os meses de menor precipitação. Os resultados podem auxiliar no planejamento de atividades agrícolas e urbanas além do melhor uso eficiente da água para o município de Leópolis.

Palavras-chave: Estação pluviométrica, probabilidade, planejamento agrícola e urbano.

\section{CHARACTERIZATION AND DISTRIBUTION OF PRECIPITATION IN THE MUNICIPALITY OF LEÓPOLIS, PR}

\begin{abstract}
The municipality of Leópolis, located in the northern part of the state of Paraná, owned pluviometric seasons been in operation since 1976, but no studies were carried out to characterize and variability of precipitation specific to the municipality, being this type information is indispensable for agricultural and urban planning. In this sense, the objective of this work was to characterize and evaluate the annual, monthly variability as well as to quantify the number of rainy and dry days, in addition to defining different levels of probability of precipitation. Rainfall data were available from the Institute of Waters of Paraná, from January 1976 to December 2017, totaling an uninterrupted record of 42 years. Precipitation in Leópolis is characterized by the highest rainfall in the period from September to May and the lowest in June to August. In the years of 2015 and 1988, the highest and lowest annual rainfall occurred respectively. The mean annual precipitation of the period was $1380.10 \mathrm{~mm}$. With the use of the incomplete gamma function, it was possible to adequately express the probability of precipitation in Leópolis, with the monthly averages of precipitation
\end{abstract}


being between 40 and $50 \%$ probability for the months of higher precipitation and between 25 and $40 \%$ for the months of lower precipitation. The results can help in the planning of agricultural and urban activities besides the best efficient use of water for the municipality of Leópolis.

Keywords: pluviometric seasons, probability, agricultural and urban planning.

\section{INTRODUÇÃO}

As medidas de dados climáticos como a temperatura e a umidade do ar, além da precipitação são importantes informações para a caracterização do clima regional, principalmente quando se têm medidas registradas em um longo período de tempo.

Normalmente a disponibilidade de estações meteorológicas que registram vários fenômenos climáticos simultaneamente são reduzidas. Contudo para dados de precipitação no estado do Paraná estão disponíveis vários postos pluviométricos, que registram a precipitação diária.

De acordo com Silva et al. (2007) A precipitação pluvial é um dos elementos meteorológicos de grande importância, pois está diretamente relacionada aos mais diversos setores da sociedade, de forma que o regime pluviométrico afeta a economia, o meio ambiente e a sociedade, como um todo.

De posse de uma série histórica de dados de precipitação é possível caracterizar e até mesmo estimar a precipitação provável do local. Em estudo composto por 22 estações meteorológicas localizadas em municípios do estado do Paraná, Sampaio et al. (2007) realizaram a estimativa e distribuição da precipitação para cada município.

A estimativa da precipitação provável é importante nas tomadas de decisões relacionadas a atividade agrícola e

\section{MATERIAL E MÉTODOS}

Os dados pluviométricos foram disponibilizados pelo Instituto das Águas do Paraná, a qual possui uma estação pluviométrica com código de identificação 2350026, localizada na região Norte do urbana do munícipio. Como meio para tal estudos indicam a distribuição gama como o meio probabilístico mais confiável na determinação de totais mensais de precipitação como verifica em Fietz et al. (1998), Dallacort et al. (2011) e TERASSI et al. (2018).

O município de Leópolis está localizado no Norte do estado do Paraná com uma área de $344,92 \mathrm{~km}^{2}$, com uma economia baseada na agropecuária (IBGE 2018). De acordo com censo agropecuário do IBGE 2016, cerca $99 \%$ da área do município destina-se a lavouras temporárias sendo a soja, milho e trigo as principais culturas.

Apesar de que no município de Leópolis, possuir três estações pluviométrica, com operações iniciadas no ano 1976 (Instituto das do Águas Paraná 2019). Ainda não fora realizado um estudo da caracterização e distribuição provável de precipitação especifica para município.

Destacada a importância no conhecimento da distribuição das precipitações pluviométrica em escala municipal, como suporte ao planejamento das atividades agrícolas e urbanas do município. Objetivou-se caracterizar e avaliar a variabilidade anual, mensal e decendial, bem como, quantificar o número de dias chuvosos e secos, além de definir diferentes níveis de probabilidade de precipitação para o município de Leópolis, norte do estado do Paraná.

Estado do Paraná no município de Leópolis, na latitude $23^{\circ} 04^{\prime} 49$ ' $S$, longitude $50^{\circ} 45^{\prime} 16^{\prime \prime} \mathrm{W}$ e altitude de $448 \mathrm{~m}$ Figura 1. A estação é composta de um pluviômetro do tipo Ville de Paris, com 
área de captação de $400 \mathrm{~cm}^{2}$, instalado sobre um suporte de $1,5 \mathrm{~m}$ de altura do solo. As leituras são realizadas diariamente as $7 \mathrm{~h}$ e $17 \mathrm{~h}$ horas, em provetas com capacidade para $10 \mathrm{~mm}$ de chuva.

O período analisado de dados pluviométricos compreendeu um período de 42 anos (1976 a 2017). Os dados foram tabulados em planilha Excel. Dados faltantes foram preenchidos com os dados provenientes de uma estação pluviométrica análoga à estação descrita anteriormente a qual possui código 2250030 localizada também no munícipio de Leópolis. Posteriormente análises de médias e desvio padrão anuais, mensais e decendiais foram realizados. Para análise de ocorrência de dias secos e chuvosos, foram considerados secos, dias em que a precipitação foi igual ou inferior a $5 \mathrm{~mm}$ e chuvosos quando a precipitação foi superior a $5 \mathrm{~mm}$ SANS et al. (2001).

A determinação de diferentes níveis de probabilidade de precipitação foi realizada, utilizando-se o modelo probabilístico de distribuição Gama incompleta THOM (1958). Dada pela função densidade probabilidade, Equação 1.

\section{RESULTADOS E DISCUSSÃO}

A precipitação anual do período avaliado apresentou um comportamento variável da distribuição das chuvas no município de Leópolis, ocorrendo a máxima precipitação de $2001,10 \mathrm{~mm}$ no ano de 2015, mínima de $963,90 \mathrm{~mm}$ no ano de 1988 e média de 1380,10 mm, apresentando desvio-padrão de 253,65 mm nos 42 anos avaliados. Avaliando a precipitação na região Norte do Estado do Paraná, Terassi et al. (2018) observaram a ocorrência de fenômenos de La Niña no 1988 e de El Niño em 2015 os quais podem influenciar à anomalias negativas e $f(x)=\frac{1}{\beta^{\alpha} \Gamma(\alpha)} x^{\alpha-1} e^{\frac{-x}{\beta}}$

em que: $\alpha$ é o parâmetro de forma (adimensional), $\beta$ é um parâmetro de escala $(\mathrm{mm}), e$ representa a base do logaritimo neperiano, $x$ é o total de precipitação e $\Gamma$ é o símbolo da função gama, definida pela Equação 2.

$$
\Gamma(\alpha+1)=\sqrt{2 \pi \alpha} \alpha^{\alpha} e^{\alpha}\left(1+\frac{1}{12 \alpha}+\frac{1}{288 \alpha^{2}}-\frac{139}{51840 \alpha^{3}}\right)
$$

Os valores dos parâmetros $\alpha$ e $\beta$ foram obtidos igualando a média $(\bar{X})$ e a variância $\left(S^{2}\right)$ da amostra à média e à variância da população, originando as Equações 3 e 4 (ASSIS et al., 1996).

$\alpha=\frac{\bar{X}^{2}}{S^{2}}$

$\beta=\frac{S^{2}}{\bar{X}}$

em que: $\bar{X}$ é a precipitação média do período $(\mathrm{mm})$ e $S^{2}$ a variância $\left(\mathrm{mm}^{2}\right)$.

Foram determinados os níveis de 10 , $25,40,50,60,75$ e $90 \%$ de probabilidade de ocorrência de chuva mensal e anual.

positivas respectivamente para a variabilidade anual das chuvas.

A distribuição anual das chuvas no município de Leópolis (Figura 1), apresentou 20 anos de precipitação acima da média (48\%). O último ano da série que apresentou precipitação inferior à média foi o ano de 2014. De acordo com Nitsche et al. (2019) a precipitação anual da região em estudo está entre 1200 e 1400 mm. Deste modo em $33 \%$ dos anos (14 anos) a precipitação esteve dentre este intervalo. 


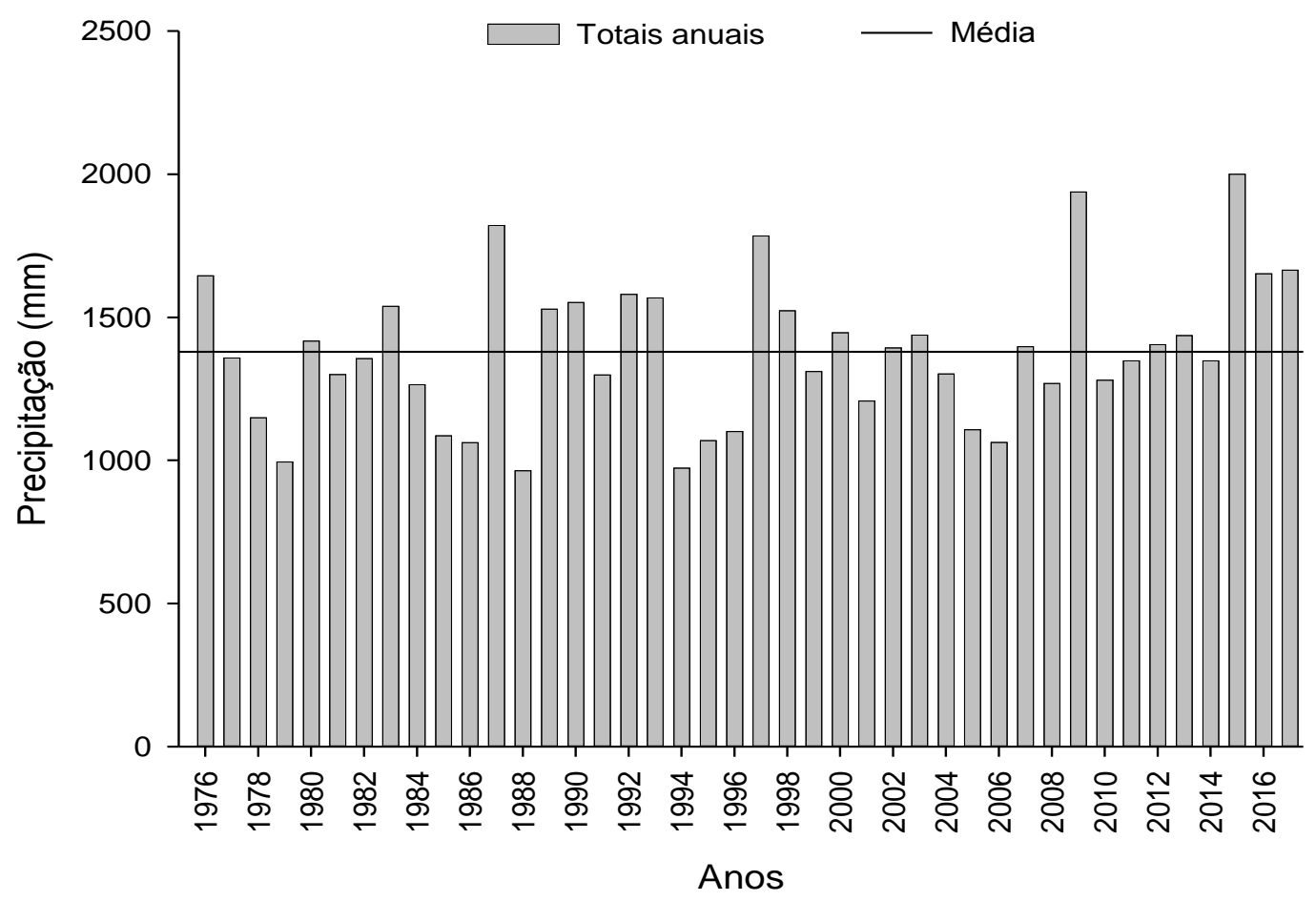

Figura 1. Distribuição pluviométrica anual no município de Leópolis, Estado do Paraná, no período de 1976 a 2017.

No período avaliado entre os anos de 1976 e 2017, os meses (Figura 2), com maiores índice pluviométricos, ocorreram de setembro a maio e os menores de junho a agosto. Sendo o mês de agosto o mais crítico para o regime hídrico, com precipitação média de $45,73 \mathrm{~mm}$. Já o mês de janeiro apresentou a maior precipitação média com 194,12 mm. De modo que os meses de janeiro e agosto apresentem os maiores e menores desvio-padrão, respectivamente. Em uma estação meteorológica no munícipio de Bela Vista do Paraiso - PR, região próxima ao local do presente estudo, Carvalho \& Stipp (2004) observaram que os meses com maior precipitação foram os de novembro, dezembro e janeiro e os meses com menor precipitação foram junho, julho e agosto.

Com relação a distribuição decendial da precipitação (Figura 3), observa-se uma variabilidade entre o quarto até o décimo quarto decêndio. Um decréscimo da precipitação decendial ocorre a partir do décimo quinto decêndio até o vigésimo segundo decêndio.

Em 8 dos 36 decêndios, o que equivale a $22 \%$, a precipitação supera os $50 \mathrm{~mm}$. O segundo e o vigésimo segundo decêndios apresentaram as maiores $\mathrm{e}$ menores médias respectivamente, nos decêndios restantes, as médias oscilaram entre 21,98 e 47,23 mm. O conhecimento prévio e confiável do regime pluviométrico para o planejamento agrícola pode reduzir significativamente os riscos de prejuízos nas atividades agropecuárias DALLACORT et al. (2011).

$\mathrm{O}$ número de dias secos e dias chuvosos no município de Leópolis (Figura 4) indica que a média foi de 59 dias chuvosos e 306 dias secos. Com 84 dias o ano de 2015 correspondeu com o maior número de dias chuvosos, enquanto com 38 dias o ano de 1978 teve menor período chuvoso. 


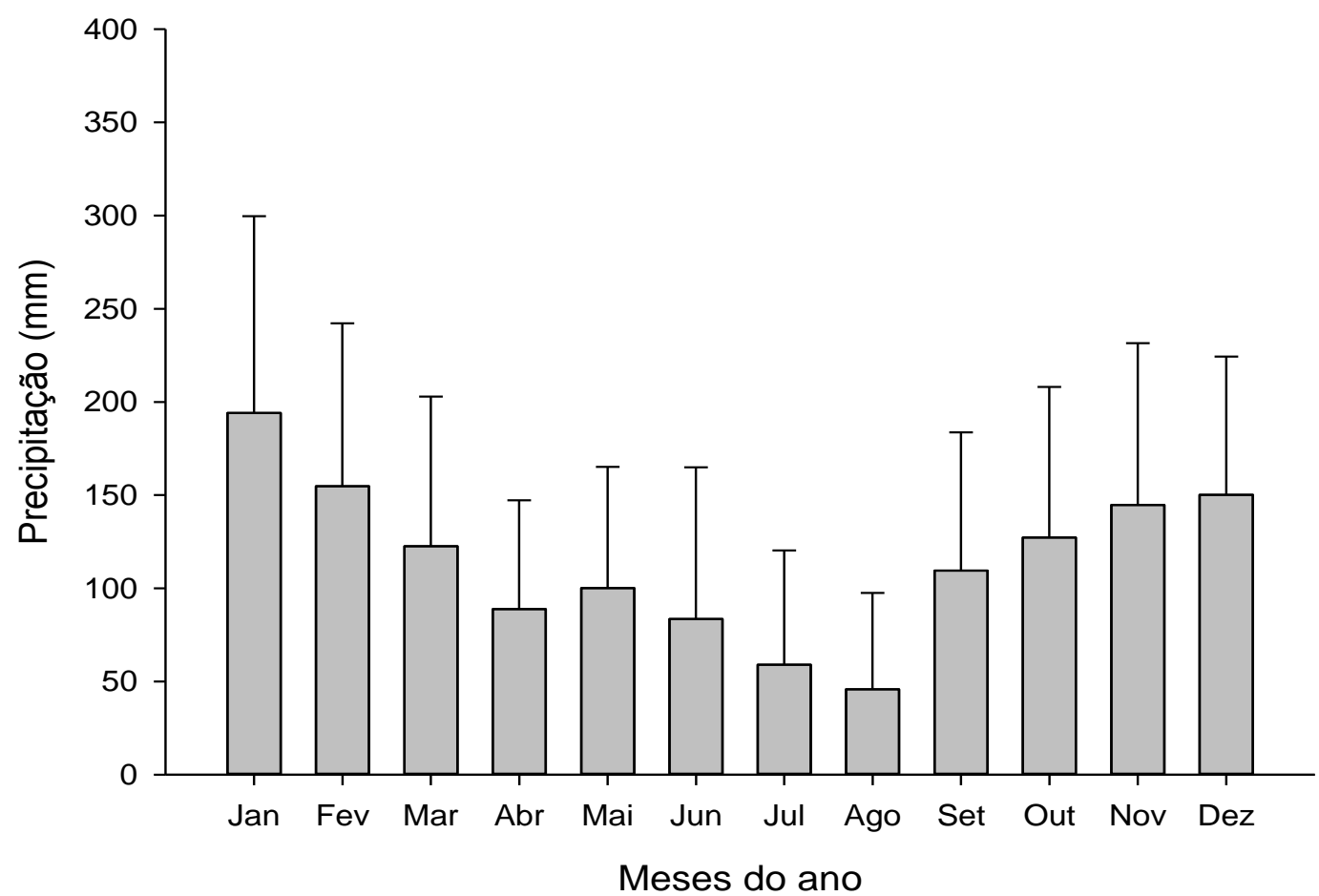

Figura 2. Médias mensais e desvio-padrão da precipitação no Município de Leópolis, Estado do Paraná.

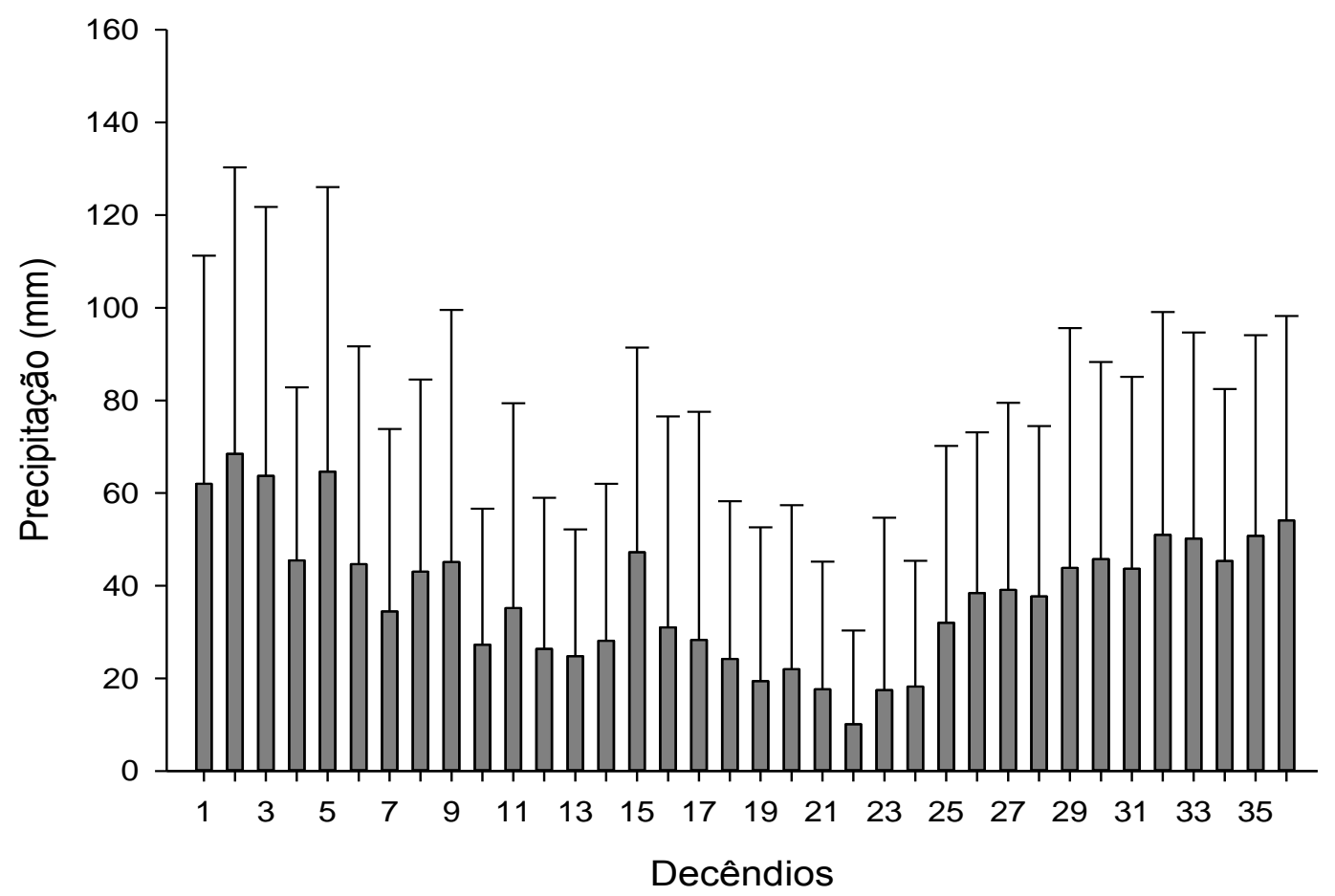

Figura 3. Médias pluviométricas decendiais e desvio padrão da precipitação pluviométrica para o município de Leópolis, Estado do Paraná no período de 1976 a 2017. 


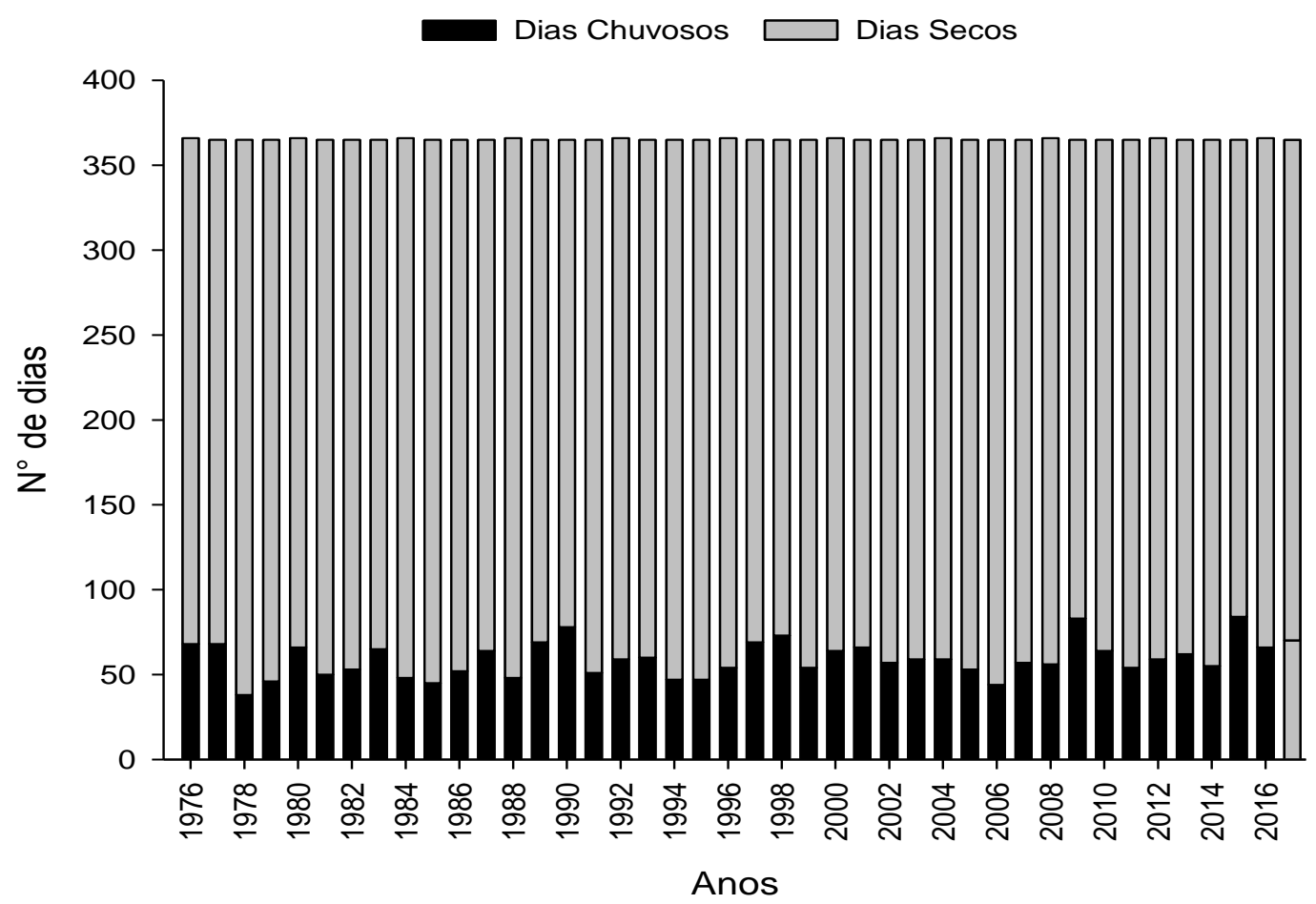

Figura 4. Ocorrência anual de dias chuvosos e secos no munícipio de Leópolis, Estado do Paraná, para o período de 1976 a 2017.

Ao longo de 42 anos de dados de precipitação o comportamento da ocorrência média mensal de dias chuvosos e secos (Figura 5), demonstra no período de outubro a fevereiro o maior número de dias chuvosos com médias entre 6 a 8 dias. Já o período de abril a agosto é caracterizado pela menor ocorrência de dias chuvosos com médias entre 2 a 4 dias. Os meses de março, setembro e outubro foram intermediários com 5 dias em média de dias chuvosos. De acordo com Sampaio et al. (2007) o estado do Paraná apresenta as maiores precipitações prováveis decendiais nos meses de outubro a fevereiro e os menores nos meses de julho e agosto.

Pela distribuição Gama foi possível determinar a precipitação provável mensal e anual para o munícipio de Leópolis (Tabela 1). De acordo com Longo et al. (2006), em nível de $5 \%$ de significância a distribuição Gama apresenta melhores ajustes de séries históricas de precipitação no estado do Paraná.

Entre os meses de setembro a abril a média pluviométrica mensal mante-se entre os níveis de 40 a $50 \%$ de probabilidade. Enquanto que no período de maio a agosto, a probabilidade de ocorrência média reduziu entre 25 a $40 \%$. Em meses com menor índice de precipitação, a variação temporal é mais acentuada, existindo maior probabilidade na ocorrência de valores abaixo da média do que iguais ou acima da mesma DALLACORT et al. (2011).

Em níveis de 75, 50 e $25 \%$ o mês de janeiro apresenta a maior precipitação provável, com 116,$65 ; 175,36$ e 251,29 mm respectivamente.

Com as menores precipitações prováveis o período com maior deficiência hídrica no município de Leópolis, é compreendido pelos meses de junho, julho e agosto. No mês de junho existe a probabilidade de $75 \%$ de as precipitações serem iguais ou maiores a $24,27 \mathrm{~mm}$. Para os meses de julho e agosto as probabilidades foram de 15,64 e 9,89 mm respectivamente. De acordo com Terassi et al. (2016), a região Norte e Noroeste do estado do Paraná é caracterizada por uma tropicalização climática nos setores mais setentrionais e de menores cotas altimétricas, o que caracteriza as menores médias de pluviosidade nos meses de junho, julho e agosto na região. 


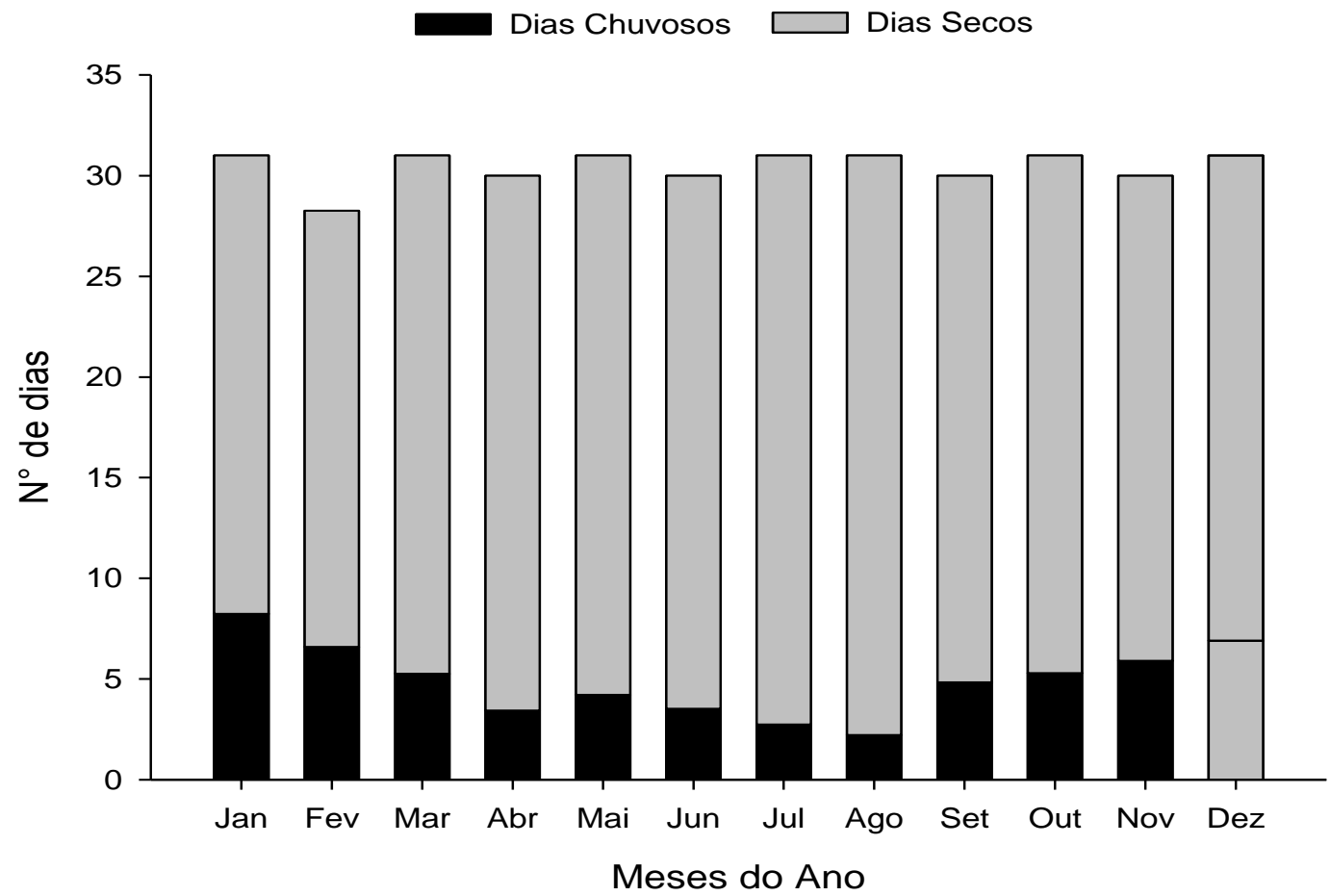

Figura 5. Ocorrência média mensal de dias chuvosos e secos no munícipio de Leópolis, Estado do Paraná, para o período de 1976 a 2017.

A média da precipitação encontra-se entre os valores de 40 e $50 \%$ de probabilidade. Correspondendo a 1364,59 e $1429,43 \mathrm{~mm}$

O estudo da caracterização e da respectivamente. Segundo Castro \& Leopoldo (1995) a recomendação técnica para elaboração de projetos de irrigação deve ser em níveis entre 75 e $80 \%$ de probabilidade. distribuição pluviométrica e de como
prevê-la mensalmente ou anualmente, são importantes no planejamento das atividades agrícolas e urbanas. Além do melhor uso eficiente da água disponível.

Tabela 1. Parâmetros $(\alpha)$ e beta $(\beta)$ da distribuição gama para precipitação provável mensal e anual para o munícipio de Leópolis, estado do Paraná.

\begin{tabular}{lccccllllll}
\hline \multirow{2}{*}{ Mês } & \multirow{2}{*}{ Média } & $\alpha$ & \multirow{2}{*}{$\beta$} & \multicolumn{7}{c}{ Níveis de probabilidade } \\
\cline { 5 - 10 } & & & & $90 \%$ & $75 \%$ & $60 \%$ & $50 \%$ & $40 \%$ & $25 \%$ & $10 \%$ \\
\hline Jan & 194,12 & 3,38 & 57,39 & 76,98 & 116,65 & 151,38 & 175,36 & 201,77 & 251,29 & 335,65 \\
Fev & 154,71 & 3,12 & 49,56 & 58,34 & 90,39 & 118,79 & 138,54 & 160,38 & 201,54 & 272,12 \\
Mar & 122,57 & 2,32 & 52,73 & 37,23 & 63,45 & 87,98 & 105,51 & 125,26 & 163,29 & 230,20 \\
Abr & 88,79 & 2,31 & 38,44 & 26,83 & 45,83 & 63,62 & 76,35 & 90,70 & 118,34 & 167,00 \\
Mai & 110,12 & 2,38 & 42,15 & 30,96 & 52,35 & 72,26 & 86,47 & 102,46 & 133,17 & 187,11 \\
Jun & 83,50 & 1,05 & 79,35 & 9,64 & 25,27 & 43,94 & 59,03 & 77,36 & 115,70 & 189,86 \\
Jul & 59,01 & 0,93 & 63,76 & 5,36 & 15,64 & 28,72 & 39,61 & 53,08 & 81,80 & 138,48 \\
Ago & 45,73 & 0,78 & 58,49 & 2,87 & 9,89 & 19,74 & 28,32 & 39,24 & 63,17 & 111,82 \\
Set & 109,48 & 2,18 & 50,33 & 31,43 & 54,92 & 77,19 & 93,24 & 111,40 & 146,55 & 208,78 \\
Out & 127,23 & 2,47 & 51,44 & 40,63 & 67,74 & 92,77 & 110,55 & 130,50 & 168,73 & 235,59 \\
Nov & 144,74 & 2,78 & 52,10 & 50,42 & 80,90 & 108,44 & 127,79 & 149,34 & 190,27 & 261,14 \\
Dez & 150,13 & 4,09 & 36,71 & 66,25 & 95,78 & 120,95 & 138,08 & 156,77 & 191,43 & 249,62 \\
\hline Anual & 1380,10 & 29,60 & 46,62 & 1066,64 & 1201,62 & 1301,75 & 1364,59 & 1429,43 & 1541,69 & 1713,51 \\
\hline
\end{tabular}




\section{CONCLUSÕES}

A distribuição das precipitações apresentou variabilidade temporal anual de 2001,$10 ; 963,90$ e $1380,10 \mathrm{~mm}$, para máxima, mínima e média respectivamente.

Os maiores índice pluviométricos, ocorreram de setembro a maio e os menores de junho a agosto. A média anual

\section{REFERÊNCIAS BIBLIOGRÁFICAS}

ASSIS, F. N.; ARRUDA, H. V.; PEREIRA, A. R. Aplicações de estatística à climatologia: teoria e prática. Pelotas: Universidade Federal de Pelotas, 1996.

CARVALHO, S. M.; STIPP, N. A. F. Contribuição ao estudo do balanço hídrico no estado do Paraná: uma proposta de classificação qualitativa. Geografia, v. 13, (1): 57-71, 2004.

CASTRO, R.; LEOPOLDO, P. R. Ajuste da distribuição gama incompleta na estimativa da precipitação pluviométrica provável para os períodos de 15 e 10 dias da cidade de São Manuel (SP). Energia na Agricultura, v. 10, (1): 20-28, 1995.

DALLACORT, R.; MARTINS, J. A.; INOUE, M. H.; FREITAS, P. S. L.; COLETTI, A. J. Distribuição das chuvas no município de Tangará da Serra, médio norte do Estado de Mato Grosso, Brasil. Acta Scientiarum. Agronomy, v. 33, (2): 193-200, 2011.

FIETZ, C. R.; FRIZZONE, J. A.; FOLEGATTI, M. V.; URCHEI, M. A. Precipitação esperada, em diferentes níveis de probabilidade, na região de Dourados, MS. Ciência Rural, v. 28, (1): 29-34, 1998.

IBGE - INSTITUTO BRASILEIRO DE GEOGRAFIA E ESTATÍSTICA. Área territorial - Brasil, Grandes Regiões, Unidades da Federação e Municípios. Rio de Janeiro, 2018. Disponível em: https://www.ibge.gov.br/geociencias/organ izacao-do-territorio/estrutura- de dias chuvosos para o período avaliado foi de 59 dias e 306 dias secos. Sendo o mês de agosto o mais crítico para o regime hídrico do município.

Pela distribuição gama incompleta a precipitação provável da média anual esteve entre 40 e $50 \%$ de probabilidade.

territorial/15761-areas-dosmunicipios.html?t=acesso-aoproduto \&c $=4113403$. Acessado em: 03 de junho de 2019.

IBGE - INSTITUTO BRASILEIRO DE
GEOGRAFIA Produção Agrícola Municipal - PAM. Rio de Janeiro, 2016. Disponível em: https://www.ibge.gov.br/estatisticas/econo micas/agricultura-e-pecuaria/2046-npproducao-agricola-municipal/9117producao-agricola-municipal-culturastemporarias-epermanentes.html?=\&t=downloads. Acessado em: 03 de junho de 2019.

INSTITUTO DAS ÁGUAS PARANÁ. Sistema de Informações Hidrológicas/ Relatório de Alturas de Precipitação (diário). Curitiba, 2019. Disponível em: http://www.sih-

web.aguasparana.pr.gov.br/sihweb/gerarRelatorioAlturasDiariasPrecipita cao.do?action $=$ carregarInterfaceInicial Acessado em: 03 de junho de 2019.

LONGO, A. J.; SAMPAIO, S. C.; QUEIROZ, M. M. F.; SUSZEK, M. Uso das distribuições gama e log-normal na estimativa de precipitação provável quinzenal. Artigos \& Ensaios, v. 6, (11), 107-118, 2006.

NITSCHE, P. R.; CARAMORI, P. H.; RICCE, W. DA S.; PINTO, L. F. D. Atlas climático do Estado do Paraná. Londrina: Instituto Agronômico do Paraná, 2019. 
SAMPAIO, S. C.; QUEIROZ, M. F.; FRIGO, E. P.; LONGO, A. J.; SUSZEK, M. Estimativa e distribuição de precipitações decendiais para o Estado do Paraná. Irriga, v. 12, (1): 38-53, 2007.

SANS, L. M. A.; ASSAD, E. D.; GUIMARÃES, D. P.; AVELLAR, G. Zoneamento de riscos climáticos para a cultura de milho na Região Centro-Oeste do Brasil e para o estado de Minas Gerais. Revista Brasileira de Agrometeorologia, v. 9, (3): 527-535, 2001.

SILVA, J. C.; HELDWEIN, A. B.; MARTINS, F. B.; TRENTIN, G.; GRIMM, E. L. Análise de distribuição de chuva para Santa Maria, RS. Revista Brasileira de Engenharia Agrícola e Ambiental, v. 11, (1): 67-72, 2007.
TERASSI, P. M. B.; OLIVEIRA-JÚNIOR, J. F.; GÓIS, G.; GALVANI, E. Variabilidade do Índice de Precipitação Padronizada na Região Norte do Estado do Paraná Associada aos Eventos de El NiñoOscilação Sul. Revista Brasileira de Meteorologia, v. 33, (1): 11-25, 2018.

TERASSI, P. M. B.; SILVEIRA, H.; GRAÇA, C. H. Regiões pluviométricas homogêneas e a erosividade das chuvas na unidade hidrográfica Pirapó, Paranapanema III e IV-Paraná. Caderno de Geografia, v. 26, n. 46, p. 507-521, 2016.

THOM, H. C. S. A note on the Gamma Distribution. Monthly Weather Review, v. 86, n. 4, p. 117-122, 1958. 